\title{
Stator and Rotor Faults Diagnosis of Squirrel Cage Motor Based on Fundamental Component Extraction Method
}

\author{
Guoqing $\mathrm{An}^{1,2}$ and Hongru $\mathrm{Li}^{1}$ \\ ${ }^{1}$ Mechanical Engineering College, Shijiazhuang 050003, China \\ ${ }^{2}$ Hebei University of Science and Technology, Shijiazhuang 050018, China \\ Correspondence should be addressed to Hongru Li; lihr168@sohu.com
}

Received 19 February 2017; Accepted 13 April 2017; Published 8 May 2017

Academic Editor: Zhixiong Li

Copyright (c) 2017 Guoqing An and Hongru Li. This is an open access article distributed under the Creative Commons Attribution License, which permits unrestricted use, distribution, and reproduction in any medium, provided the original work is properly cited.

Nowadays, stator current analysis used for detecting the incipient fault in squirrel cage motor has received much attention. However, in the case of interturn short circuit in stator, the traditional symmetrical component method has lost the precondition due to the harmonics and noise; the negative sequence component (NSC) is hard to be obtained accurately. For broken rotor bars, the new added fault feature blanked by fundamental component is also difficult to be discriminated in the current spectrum. To solve the above problems, a fundamental component extraction (FCE) method is proposed in this paper. On one hand, via the antisynchronous speed coordinate (ASC) transformation, NSC of extracted signals is transformed into the DC value. The amplitude of synthetic vector of NSC is used to evaluate the severity of stator fault. On the other hand, the extracted fundamental component can be filtered out to make the rotor fault feature emerge from the stator current spectrum. Experiment results indicate that this method is feasible and effective in both interturn short circuit and broken rotor bars fault diagnosis. Furthermore, only stator currents and voltage frequency are needed to be recorded, and this method is easy to implement.

\section{Introduction}

Nowadays, squirrel cage motor has been widely used in the industrial and agricultural production because of its simple and rugged construction [1]. But it is usually subjected to the unavoidable stresses, which create failures in different parts. Statistical studies have shown that interturn short circuit fault in stator accounts for nearly $30 \%-40 \%$ of total failures; the broken rotor bars fault takes nearly $10 \%$ [2-4]. Traditional noninvasive techniques are usually used to diagnose these types of fault. These strategies are based on the analysis of quantities such as vibration, voltage, current, torque, and speed [5]. With the development of modern signal processing and computer technology, some advanced diagnosis methods have been proposed recently.

In the case of interturn short circuit in stator, the traditional symmetrical component method has lost the precondition because of the harmonics and noise [6-8]. The NSC as fault characteristic is hard to be obtained accurately. Reference [9] took stator negative sequence impedance as interturn short circuit fault characteristic; this method has robustness in the case of unbalanced power supply, because negative sequence impedance is the ratios of negative sequence voltage and current. But if the power supply is balanced enough, the calculation results will include error. Reference [10] extracted the vibration feature to diagnose the winding fault; unfortunately it cannot distinguish rotor partiality with the stator fault. Reference [11] utilized neural network to detect the turns of short circuit in the winding, but it usually requires a large amount of data for training. If the data is overtrained or inadequately trained, the diagnosis result would be influenced. By analyzing the changes of higher harmonics in the residual voltage after AC dump, the location of interturn short circuit in the stator winding can be found, but it is very hard to achieve the online fault diagnosis [12]. Reference [13] utilized the instantaneous power decomposition technique to improve the precision of the fault recognition under different operating conditions, but there are a lot of parameters needed to be identified. 
In the case of broken rotor bars, the presence of fault will provoke air-gap field perturbation in the stator current spectrum, and two sideband components appear in the vicinity of supply frequency, with frequencies given as follows [14]:

$$
f_{s}=f(1 \pm 2 s)
$$

where $f_{s}$ represents fault frequency, $f$ represents supply frequency, and $s$ represents slip of squirrel cage motor.

However, the spectral leakage of the fundamental component obscures the rotor fault components. It can get worse when squirrel cage motor is operated at low slip values, because the components $f_{s}$ become closer. In order to solve the problem, $[15,16]$ proposed extended Park's vector approach, and [17] proposed Hilbert modulus spectrum analysis to extract the broken bars fault feature. But the above two methods would produce some other crossed components, which make the spectrum be more complicated. Reference [18] utilized Hilbert transform to detect the broken rotor bar fault location through envelope analysis of start-up current, but it is very hard to achieve the on-line fault diagnosis. Reference [19] presented a Park vector rotating filter; the fundamental component can be removed accurately. But the algorithm needs to filter out NSC firstly, and the complicated calculation limits the application. Reference [20] utilized higher-order spectrum to detect the rotor fault, but the problem of large amount of computation needs to be solved firstly.

FCE method based on correlation analysis of current signal is proposed in this paper. In the case of interturn short circuit in stator, the method is used to avoid the effects of the harmonics and noise in current signal firstly. Then, via ASC transformation, the NSC of extracted signals is transformed into the DC value, and the amplitude of a synthetic vector of the NSC is given to evaluate the severity of stator fault. In the case of broken rotor bars, the extracted fundamental component can be filtered out accurately according to the results of FCE method, and the rotor fault components may emerge from the stator current spectrum.

The paper is organized as follows: Section 2 presents FCE method, and the implementation of this method is introduced in both cases of interturn short circuit and broken rotor bars fault diagnosis. Section 3 presents the structure frame of fault diagnosis system. Section 4 presents a favorable discussion and analysis of the experimental results. Finally, our conclusions are provided in Section 5.

\section{Algorithm of FCE}

2.1. FCE Method. Correlation function describes the relationship between one instantaneous value $x(t)$ and another one $x(t+\tau)$. The self-correlation and cross-correlation functions are defined as the follows:

$$
\begin{aligned}
R_{x}(\tau) & =E[x(t) x(t+\tau)] \\
& =\lim _{t \rightarrow \infty} \frac{1}{T} \int_{0}^{T} x(t) x(t+\tau) d t,
\end{aligned}
$$

$$
\begin{aligned}
R_{x y}(\tau) & =E[x(t) y(t+\tau)] \\
& =\lim _{t \rightarrow \infty} \frac{1}{T} \int_{0}^{T} x(t) y(t+\tau) d t,
\end{aligned}
$$

where $T$ represents signal period and $\tau$ represents time difference.

Now there are two signals expressed as

$$
\begin{aligned}
& x(t)=A_{x} \sin (\omega t+\theta), \\
& y(t)=A_{y} \sin \left(\omega t+\theta-\varphi_{x y}\right),
\end{aligned}
$$

where $A_{x}$ and $A_{y}$ represent amplitude, $\omega$ represents radian frequency, $\theta$ represents phase angle, and $\varphi_{x y}$ represents phase difference.

Because $T$ is finite, the estimate of cross-correlation between $x(t)$ and $y(t)$ can be described as follows:

$$
\begin{aligned}
& \hat{R}_{x y}(\tau)=\frac{1}{T} \\
& \quad \cdot \int_{0}^{T} A_{x} \sin (\omega t+\theta) A_{y} \sin \left(\omega(t+\tau)+\theta-\varphi_{x y}\right) d t \\
& \quad=\frac{1}{2} A_{x} A_{y} \cos \left(\omega \tau-\varphi_{x y}\right) .
\end{aligned}
$$

In (4), it can be concluded that the frequency information and phase information are both reserved.

Now a sinusoidal signal containing noise is given as follows:

$$
s(t)=A \sin (\omega t+\varphi)+n(t),
$$

where $A$ represents amplitude of sinusoidal component, $\varphi$ represents phase angle, and $n(t)$ indicates noise.

Then two reference signals which have the same frequency with $s(t)$ can be constructed:

$$
\begin{aligned}
& z_{1}(t)=B \sin (\omega t), \\
& z_{2}(t)=B \cos (\omega t),
\end{aligned}
$$

where $B$ represents amplitude of the reference signals.

There is no correlation of $n(t)$ with $z_{1}(t)$ and $z_{2}(t)$, so the estimate of cross-correlation between $s(t)$ and $z_{1}(t)$ and $z_{2}(t)$ can be described as follows:

$$
\begin{aligned}
& R_{s z 1}=\frac{1}{T} \int_{0}^{T} s(t) z_{1}(t) d t=\frac{1}{2} A B \cos (\varphi), \\
& R_{s z 2}=\frac{1}{T} \int_{0}^{T} s(t) z_{2}(t) d t=\frac{1}{2} A B \sin (\varphi) .
\end{aligned}
$$
follows:

By (7), the phase angle and amplitude can be expressed as

$$
\begin{aligned}
& \varphi=\operatorname{arctg}\left(\frac{R_{s z 2}}{R_{s z 1}}\right), \\
& A=\frac{2 R_{s z 1}}{(B \cos (\varphi))} .
\end{aligned}
$$

In this way, the fundamental component can be extracted from stator current accurately. 
2.2. Application of FCE Method in Stator Short Circuit Fault Diagnosis. Stator interturn short circuit fault would cause the imbalance of three-phase current. Due to harmonics and noise in stator current, the traditional symmetrical component method has lost the precondition; the NSC is hard to be obtained accurately. Therefore, FCE method can be applied in the stator fault diagnosis.

In the remainder of this paper, phase $A$ will be taken as the example for discussion. It is assumed that phase current signal is recorded as $N$ points in period $T$. The discrete-time array of current is named as $i_{A}\left(t_{k}\right)$. According to (6), the arrays corresponding to reference signals are noted as $z_{1}\left(t_{k}\right)$ and $z_{2}\left(t_{k}\right)$, respectively, where $t_{k}=0,1,2, \ldots, N-1$. The estimate of cross-correlation $R_{I z 1}$ and $R_{I z 2}$ between $i_{A}\left(t_{k}\right)$ and $z_{1}\left(t_{k}\right)$ and $z_{2}\left(t_{k}\right)$ can be expressed as follows:

$$
\begin{aligned}
& R_{I z 1}=\frac{1}{N} \sum_{t_{k}=0}^{N-1} i_{A}\left(t_{k}\right) z_{1}\left(t_{k}\right), \\
& R_{I z 2}=\frac{1}{N} \sum_{t_{k}=0}^{N-1} i_{A}\left(t_{k}\right) z_{2}\left(t_{k}\right) .
\end{aligned}
$$

By (8), it is easy to obtain the amplitude and phase of fundamental component in the stator phase current. The same method can be used to calculate the values of phases $B$ and $C$. Then fundamental component of three-phase current can be expressed as follows:

$$
\left[\begin{array}{l}
i_{A 1}\left(t_{k}\right) \\
i_{B 1}\left(t_{k}\right) \\
i_{C 1}\left(t_{k}\right)
\end{array}\right]=\left[\begin{array}{l}
I_{A 1 M} \cos \left(\omega t_{k}+\varphi_{A 1}\right) \\
I_{B 1 M} \cos \left(\omega t_{k}+\varphi_{B 1}\right) \\
I_{C 1 M} \cos \left(\omega t_{k}+\varphi_{C 1}\right)
\end{array}\right],
$$

where $I_{A 1 M}, I_{B 1 M}$, and $I_{C 1 M}$ represent the amplitudes of fundamental component and $\varphi_{A 1}, \varphi_{B 1}$, and $\varphi_{C 1}$ represent the phase angles of fundamental component.

Since the extraction of DC component is much easier in signal processing, a method based on ASC transformation is applied for NSC calculation. In this coordinate, the positive sequence component is turned into the second harmonic, and NSC is transformed into the DC component, which can be extracted by the mean algorithm. Then the extracted DC component can be used to evaluate the severity of the interturn short circuit fault in the stator. The matrix from three-phase coordinate $(a, b, c)$ to the $\operatorname{ASC}(d, q)$ is given by

$$
C_{N 3 \rightarrow 2}=\sqrt{\frac{2}{3}}\left[\begin{array}{ccc}
\cos \left(\omega_{1} t+\theta_{0}\right) & \cos \left(\omega_{1} t+\theta_{0}+\frac{2}{3} \pi\right) & \cos \left(\omega_{1} t+\theta_{0}-\frac{2}{3} \pi\right) \\
-\sin \left(\omega_{1} t+\theta_{0}\right) & -\sin \left(\omega_{1} t+\theta_{0}+\frac{2}{3} \pi\right) & -\sin \left(\omega_{1} t+\theta_{0}-\frac{2}{3} \pi\right) \\
\frac{1}{\sqrt{2}} & \frac{1}{\sqrt{2}} & \frac{1}{\sqrt{2}}
\end{array}\right]
$$

where $\omega_{1}$ represents radian frequency of stator voltage, $\theta_{0}$ represents initial angle between $a$-axis in stationary coordinate and $d$-axis in rotating coordinate. In the ASC, the fundamental component can be expressed as follows:

$$
\begin{aligned}
& {\left[\begin{array}{lll}
i_{d}\left(t_{k}\right) & i_{q}\left(t_{k}\right) & i_{0}\left(t_{k}\right)
\end{array}\right]^{T}} \\
& =C_{N 3 \rightarrow 2}\left[i_{A 1}\left(t_{k}\right) i_{B 1}\left(t_{k}\right) i_{C 1}\left(t_{k}\right)\right]^{T},
\end{aligned}
$$

where the $d$-axis component is noted as $i_{d}\left(t_{k}\right), q$-axis component is noted as $i_{q}\left(t_{k}\right)$, and zero sequence component is noted as $i_{0}\left(t_{k}\right)$.

Adjust the sampling time to be integer multiple of the supply power period. Via the mean algorithm, the NSC which has been turned into DC one can be extracted. Meanwhile the positive sequence component which has been turned into the second harmonic can be filtered out. Zero sequence component $i_{0}$ is small enough to be ignored:

$$
\begin{aligned}
& I_{-d}=\frac{1}{N} \sum_{t_{k}=0}^{N-1} i_{d}\left(t_{k}\right), \\
& I_{-q}=\frac{1}{N} \sum_{t_{k}=0}^{N-1} i_{q}\left(t_{k}\right),
\end{aligned}
$$

where $I_{-d}$ represents the value of NSC projected on $d$-axis and $I_{-q}$ represents the one projected on $q$-axis in the ASC.

The amplitude of a synthetic vector $I_{-M}$ is given as

$$
I_{-M}=\sqrt{I_{-d}^{2}+I_{-q}^{2}} \text {. }
$$

In order to evaluate the severity of the interturn short circuit, a sensitivity factor $\lambda$ which takes into account the manufactured asymmetry is defined as

$$
\lambda=20 \lg \left(\frac{I_{-M f}}{I_{-M n}}\right),
$$

where $I_{-M f}$ indicates the amplitude of synthetic vector in fault status and $I_{-M n}$ indicates the value in healthy status with the same load.

When the motor is healthy, the value of sensitivity factor $\lambda$ is zero. With the greater fault severity, $\lambda$ will increase as well. So it can be used to reflect the trend of the severity of interturn short circuit.

2.3. Application of FCE Method in Broken Rotor Bars Fault Diagnosis. To cope with the problem that spectral leakage coming from the fundamental component obscures rotor 


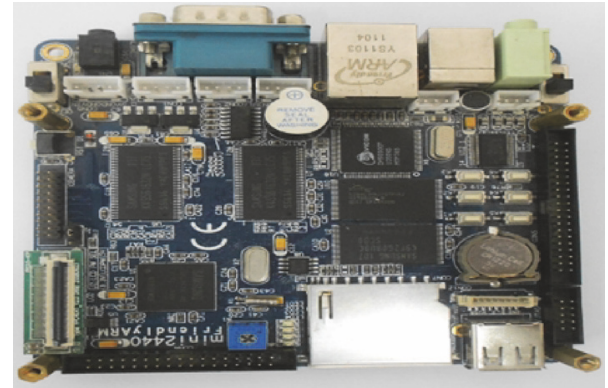

FIgURE 1: The S3C2410X ARM board.

fault feature, FCE method can also be used to filter out the fundamental component accurately. Because the fault feature can be included in spectrum of phase current, only one-phase current signal is needed to be recorded in rotor fault diagnosis. The capacity of power grid is large enough; it can be seen that the stator voltage and the fundamental component in stator current have the same frequency. Therefore, reference signals whose frequency is equal to the one of stator voltage can be constructed. Then correlation analysis between the reference signals and stator current signal can be finished. The reference signals have no correlation with the harmonics and noise; it is easy to obtain the amplitude and phase of fundamental component via some simple data processing. The detailed realizing method is discussed below.

It is assumed that there are $N$ points recorded in period $T$. The discrete-time array is noted as $i\left(t_{k}\right)$. According to (6), construct two reference signals. By (7) and (8), it is easy to obtain the amplitude $I_{r M 1}$ and phase $\varphi_{r 1}$ of fundamental component of phase current. In order to eliminate the interference of the fundamental component to the fault feature, the signal $r\left(t_{k}\right)$ is given as follows:

$$
r\left(t_{k}\right)=i\left(t_{k}\right)-I_{r M 1} \sin \left(\omega t_{k}+\varphi_{r 1}\right) .
$$

The signal $r\left(t_{k}\right)$ can be reserved for the further analysis in the spectrum.

\section{Fault Diagnosis System for Squirrel Cage Motor}

The 32-bit microprocessor S3C2410X is taken as the core of stator current signal sampling. S3C2410X's on-chip A/D converter transforms the input signal into 10-bit binary digital codes at a maximum conversion rate of $500 \mathrm{ksps}$ with $2.5 \mathrm{MHz}$ A/D converter clock [21]. The snapshot of S3C2410X ARM board is shown in Figure 1.

The signal conditioning board includes three-phase current conditioning circuit, voltage frequency conditioning circuit, and motor speed conditioning circuit. The snapshot of circuit board is shown in Figure 2.

Via LabWindows/CVI software installed on the upper computer, the MCE method is applied to the interturn short circuit and broken rotor bars fault diagnosis, respectively. The structure frame of the system is shown in Figure 3.

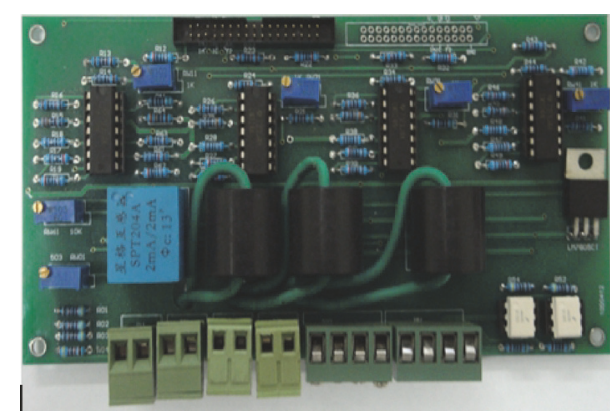

FIGURE 2: The signal conditioning board.

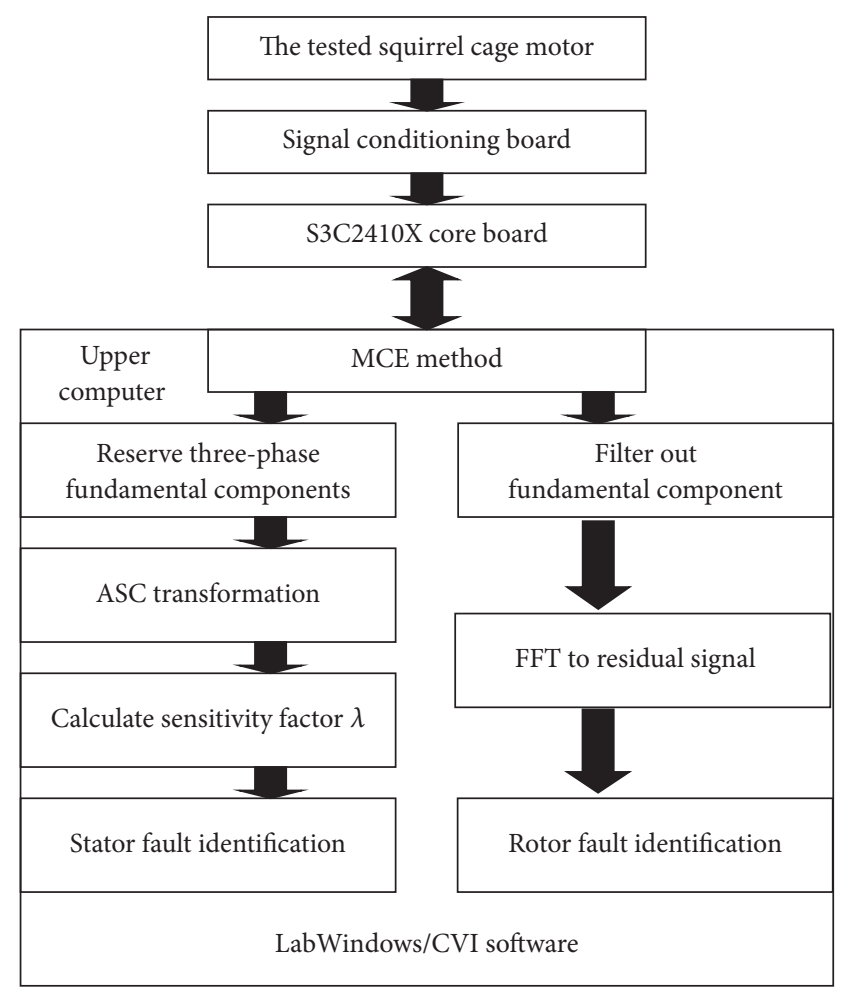

FIgURE 3: The structure frame of fault diagnosis system.

\section{Experimental Results}

4.1. Results of Interturn Short Circuit Fault Diagnosis. The tested motor's type is JO2-32-4. Its rated power is $3 \mathrm{~kW}$, and rated speed is $1400 \mathrm{r} / \mathrm{min}$. The load on the motor is changed by varying the exciting current of a magnetic powder brake. The motor experimental system is manifested in Figure 4.

The three-phase stator current signals, including healthy, one turn of short circuit, three turns of short circuit, and six turns of short circuit in phase $A$, are recorded by the experimental system. The correspondent waveform is shown in Figure 5.

The amplitude and phase information of three-phase fundamental component can be got by FCE method. According to (14), the amplitude of synthetic vector $I_{-M}$ can be obtained. Then, by (15), the sensitivity factor $\lambda$ which takes manufactured asymmetry into account can be calculated. The 


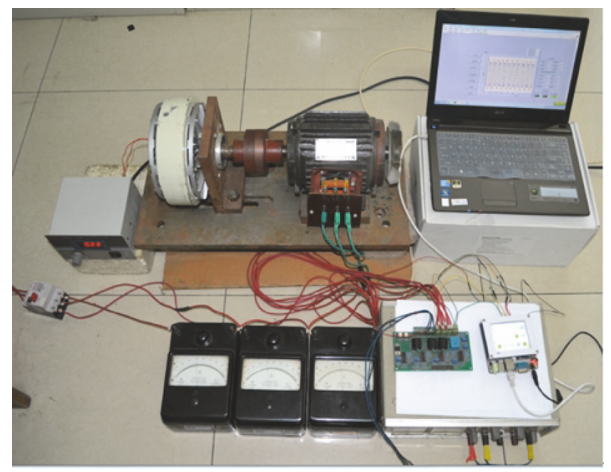

FIgURE 4: The motor experimental system.

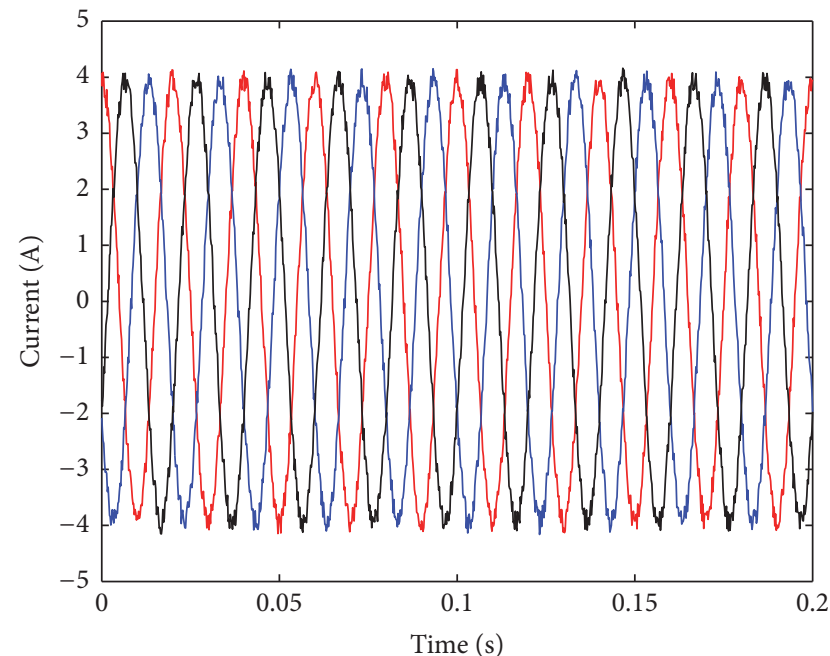

(a) No fault

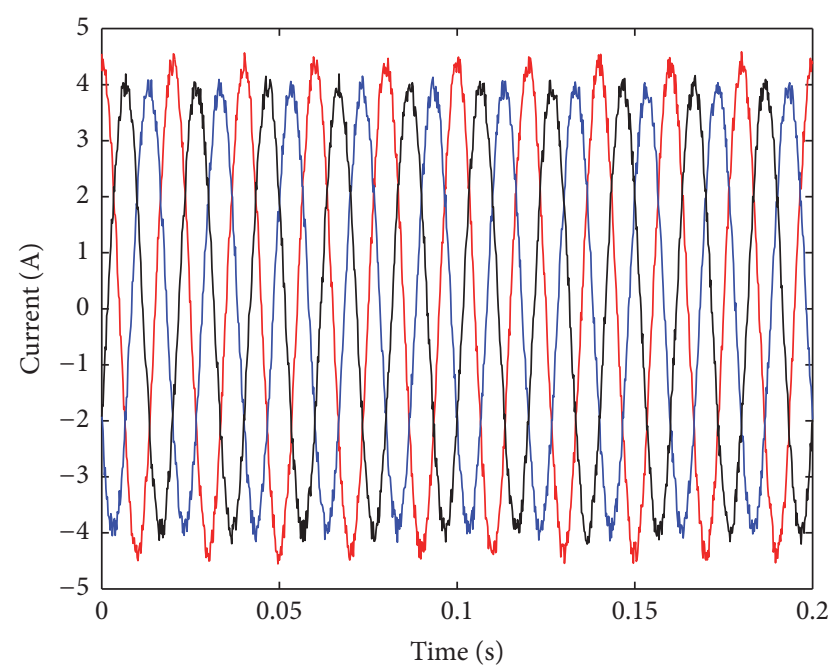

(c) Three turns of short circuit

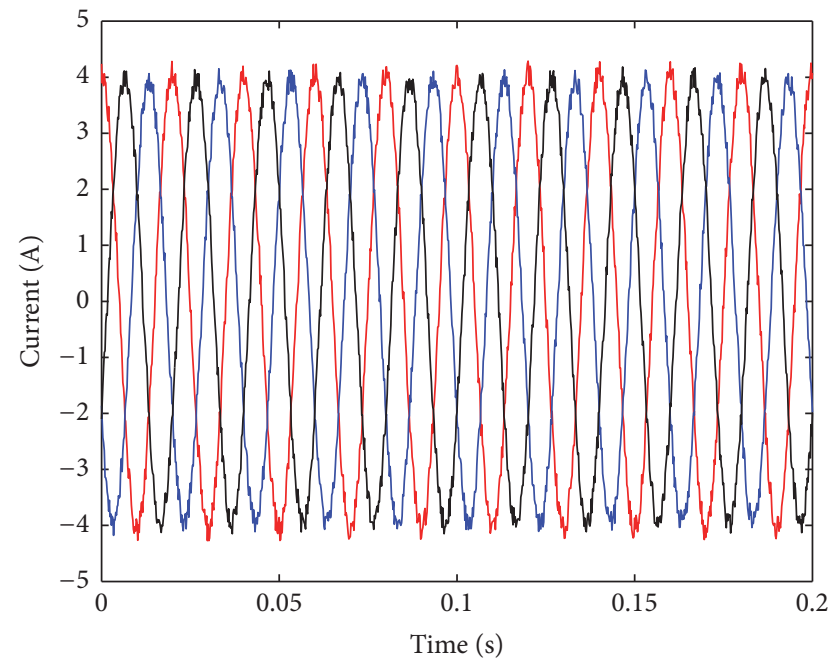

(b) One turn of short circuit

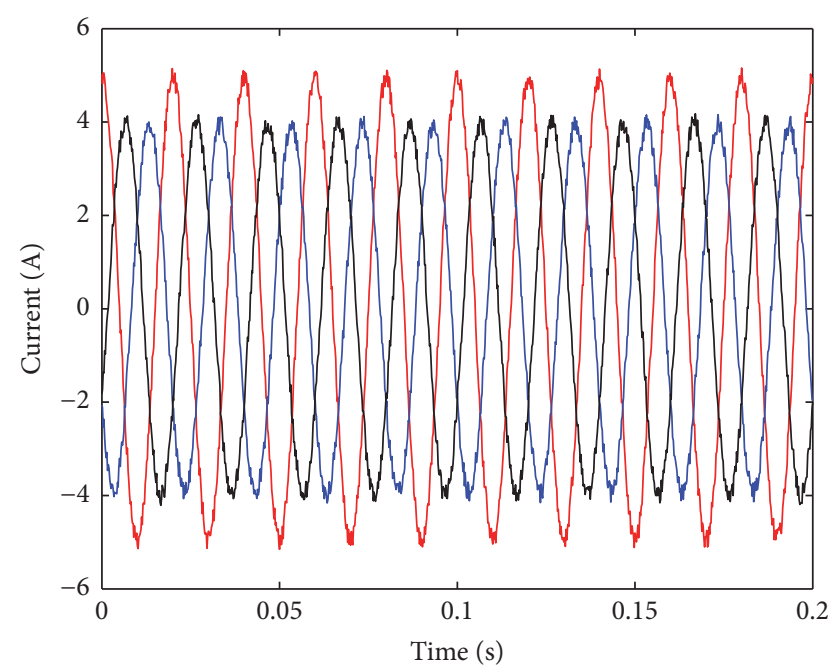

(d) Six turns of short circuit

FIGURE 5: The three-phase current waveform in different turns of short circuit. 
TABLE 1: The calculations in different turns of short circuit.

\begin{tabular}{|c|c|c|c|c|c|}
\hline Turns & $I_{A 1}(\mathrm{~A})$ & $I_{B 1}(\mathrm{~A})$ & $I_{C 1}(\mathrm{~A})$ & $I_{-M}(\mathrm{~mA})$ & $\lambda$ \\
\hline 0 & 2.799 & 2.790 & 2.794 & 8.2 & 0.00 \\
\hline 1 & 2.878 & 2.803 & 2.809 & 83.2 & 20.1 \\
\hline 3 & 3.091 & 2.798 & 2.817 & 333.3 & 32.2 \\
\hline 6 & 3.501 & 2.795 & 2.827 & 800.2 & 39.8 \\
\hline
\end{tabular}

TABLE 2: The calculations obtained by the TSC method.

\begin{tabular}{|c|c|c|c|c|c|}
\hline Turns & $I_{A}(\mathrm{~A})$ & $I_{B}(\mathrm{~A})$ & $I_{C}(\mathrm{~A})$ & $I_{-M}(\mathrm{~mA})$ & $\lambda$ \\
\hline 0 & 2.886 & 2.877 & 2.881 & 7.7 & 0.00 \\
\hline 1 & 2.967 & 2.890 & 2.897 & 70.1 & 19.2 \\
\hline 3 & 3.187 & 2.885 & 2.905 & 280.1 & 31.2 \\
\hline 6 & 3.609 & 2.882 & 2.916 & 699.8 & 39.2 \\
\hline
\end{tabular}

calculations in different turns of short circuit are shown in Table 1.

$I_{A 1}, I_{B 1}$, and $I_{C 1}$ represent effective values of fundamental component.

In order to show the effectiveness of FCE method in the interturn short circuit fault diagnosis, the calculations obtained by the traditional symmetrical component (TSC) method are shown in Table 2 [22].

$I_{A}, I_{B}$, and $I_{C}$ represent effective values of phase current.

According to the results in Tables 1 and 2, the contrast diagram of sensitivity factor is shown in Figure 6.

It can be concluded that, with the deterioration of the stator fault, the imbalance becomes more and more serious, and the value of the sensitivity factor is increased. Therefore, the defined sensitivity factor can correctly reflect on the severity of interturn short circuit fault, and it is feasible to set threshold value to decide whether to generate alerts.

Through the contrast diagram in Figure 6, it can be found that the calculations processed by FCE method are more sensitive to the short circuit fault than the ones of TSC. The influence of harmonics and noise in stator current can be effectively reduced by the FCE method, and it is proven to be more effective in the interturn short circuit fault diagnosis.

4.2. Results of Broken Rotor Bars Fault Diagnosis. The tested squirrel cage motor's type is Y90S-4. Its rated power is $1.1 \mathrm{~kW}$, rated frequency is $50 \mathrm{~Hz}$, and rated speed is $1400 \mathrm{r} / \mathrm{min}$. The load on the motor can be changed by varying the exciting current of a magnetic powder brake. The sampling frequency of the current signal is $1 \mathrm{kHz}$, and the sampling time is $1 \mathrm{~s}$. The broken bar can be generated by partial or full drilling $[23,24]$. The tested motor has one broken bar in the rotor, which is shown in Figure 7.

When the tested motor is connected to the $50 \mathrm{~Hz}$ power grid with rated load, the measured speed is $1402 \mathrm{r} / \mathrm{min}$, and the frequency values of rotor fault components based on $(1 \pm 2 s) f$ are $43.4 \mathrm{~Hz}$ and $56.6 \mathrm{~Hz}$. When the motor is operated under $50 \%$ rated load, the measured speed is up to $1462 \mathrm{r} / \mathrm{min}$. The frequency of rotor fault components based on $(1 \pm 2 s) f$ is $47.5 \mathrm{~Hz}$ and $52.5 \mathrm{~Hz}$. The local magnification of stator current spectrum is shown in Figure 8.

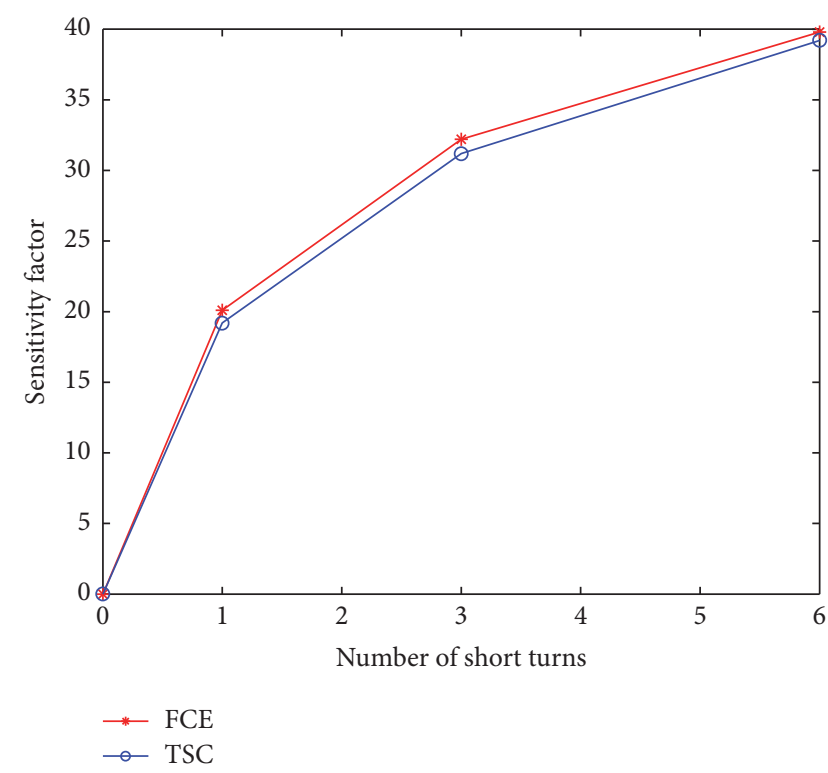

Figure 6: The contrast diagram of sensitivity factor.

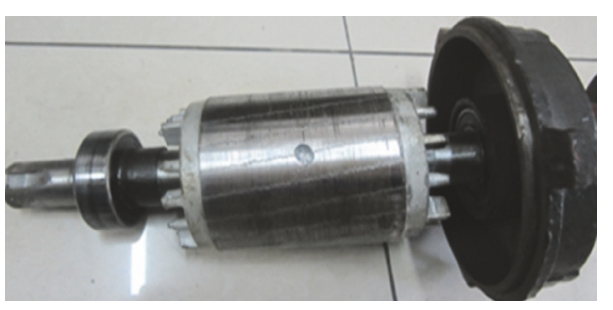

Figure 7: The rotor with one broken bar.

In Figure 8 , it can be found that the spectral leakage coming from the fundamental component obscures rotor fault components, and it is difficult to distinguish the rotor fault feature from the spectrum even by logarithmic ordinate. In the case of $50 \%$ rated load, the fault components get closer to the fundamental component, and there is little indication of rotor fault in the spectrum. 


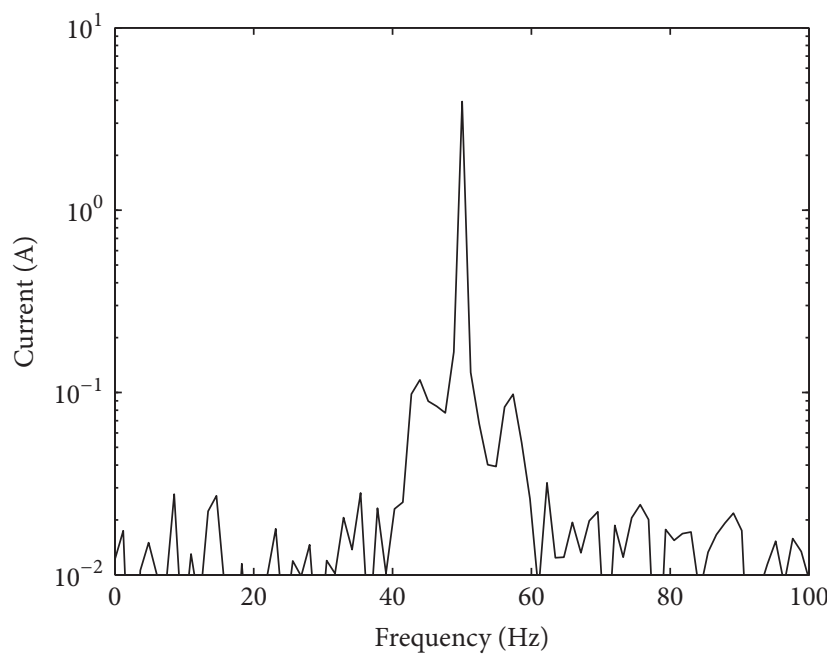

(a) Rated load

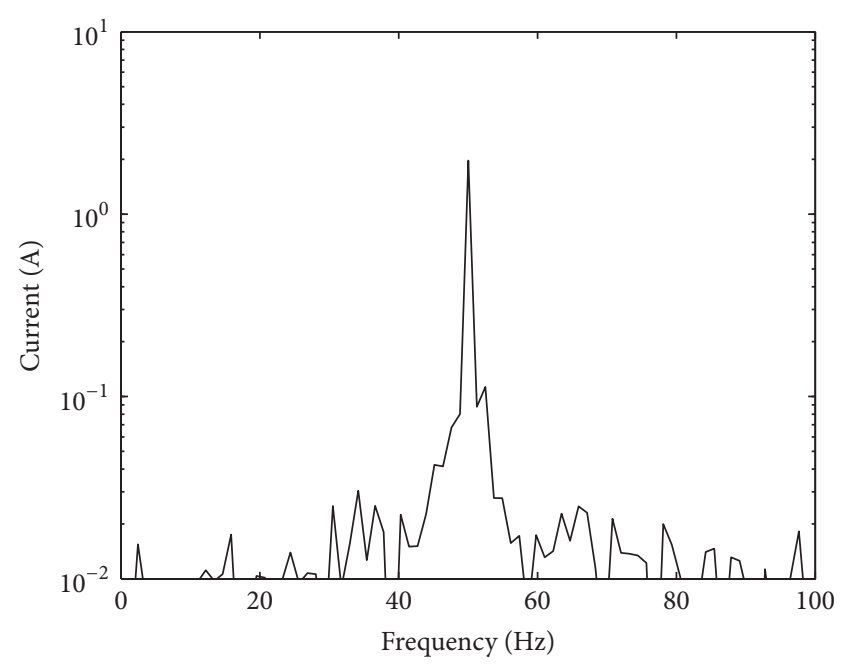

(b) $50 \%$ rated load

FIGURE 8: The local magnification of stator current spectrum.

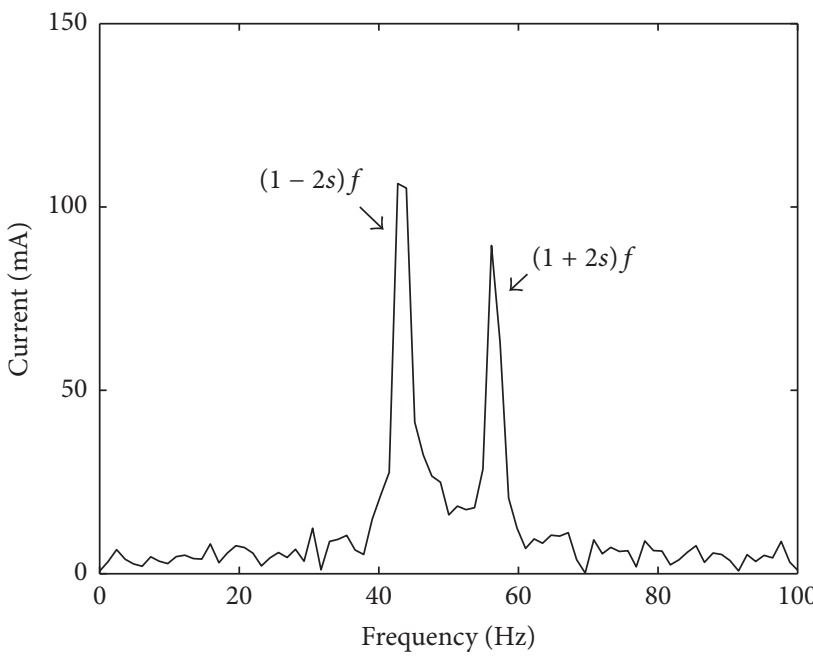

(a) Rated load

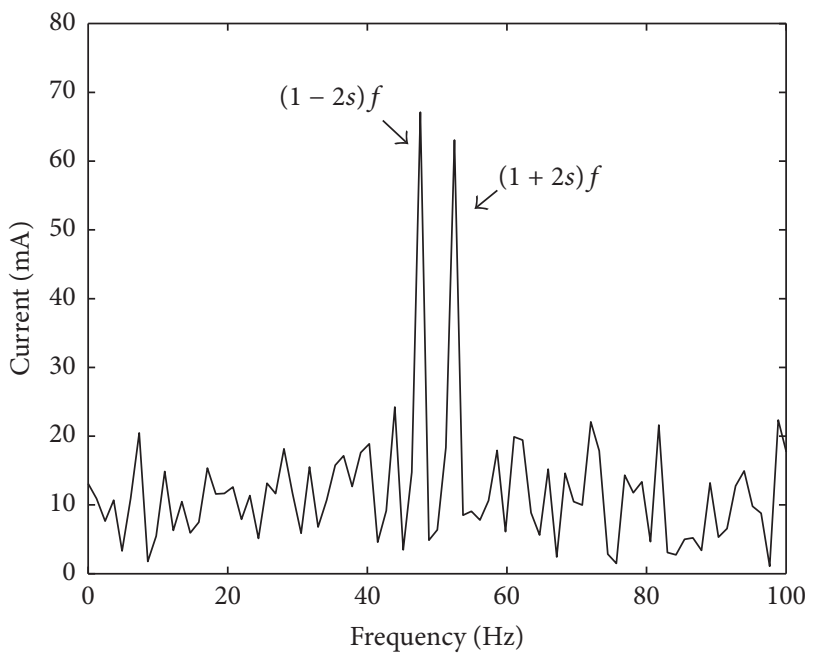

(b) $50 \%$ Rated load

FIGURE 9: The local magnification of stator current spectrum dealing with FCE method.

The local magnifications of stator current spectrums which are dealing with FCE method under 100\% and 50\% rated load are shown in Figure 9.

Figure 9 shows that the rotor fault components can emerge clearly from the spectrum, even under the light load. The experimental results have shown quite good agreement with the theory, and the FCE method can be applied in broken rotor bars diagnosis.

\section{Conclusions}

In this paper, FCE method is proposed to extract the feature in stator and rotor faults diagnosis of squirrel cage motor, respectively. Through the analysis, we can get the following conclusions:
(1) Via correlation analysis between the constructed signals and stator current signal, the amplitude and phase information of fundamental component can be obtained accurately.

(2) In the interturn short circuit fault diagnosis, the negative effects of the harmonics and noise in stator current signal can be avoided based on FCE method. The defined sensitivity factor can reflect the trend of severity of stator interturn short circuit. In addition, only single-phase short circuit is discussed in this paper, and other short circuit faults will be reported in our future work.

(3) In the broken rotor bars fault diagnosis, FCE method can be used to eliminate the interference of the fundamental component to the fault feature. The fault 
feature identification is enhanced in the stator current spectrum dealing with this method, even in the case of light load.

\section{Conflicts of Interest}

The authors declare that they have no conflicts of interest.

\section{Acknowledgments}

This project is supported by National Natural Science Foundation of China (Grant no. 51541506), Natural Science Youth Foundation of Hebei (Grant no. E2017208086), Science and Technology Research Youth Foundation for Hebei College (Grant no. QN2017329), and General Aviation Foundation of Hebei University of Science and Technology (Grant no. 201525).

\section{References}

[1] V. N. Ghate and S. V. Dudul, "Optimal MLP neural network classifier for fault detection of three phase induction motor," Expert Systems with Applications, vol. 37, no. 4, pp. 3468-3481, 2010.

[2] G. Singh, T. C. A. Kumar, and V. N. A. Naikan, "Induction motor inter turn fault detection using infrared thermographic analysis," Infrared Physics \& Technology, vol. 77, no. 7, pp. 277282, 2016.

[3] R. Sharifi and M. Ebrahimi, "Detection of stator winding faults in induction motors using three-phase current monitoring," ISA Transactions, vol. 50, no. 1, pp. 14-20, 2011.

[4] H. Çaliş and A. Çakir, "Rotor bar fault diagnosis in three phase induction motors by monitoring fluctuations of motor current zero crossing instants," Electric Power Systems Research, vol. 77, no. 5-6, pp. 385-392, 2007.

[5] W. F. Godoy, I. N. D. Silva, A. Goedtel, and R. H. C. Palácios, "Evaluation of stator winding faults severity in inverter-fed induction motors," Applied Soft Computing, vol. 32, pp. 420-431, 2015.

[6] F. Fang, S.-Y. Yang, X.-G. Hou, and Z.-G. Wu, "A novel method of calculating negative sequence current," Journal of Wuhan University of Technology, vol. 33, no. 5, pp. 872-875, 2009.

[7] P. Naderi, "Cage-rotor induction motor inter-turn short circuit fault detection with and without saturation effect by MEC model," ISA Transactions, vol. 64, no. 9, pp. 216-230, 2016.

[8] R. Roshanfekr and A. Jalilian, "Analysis of rotor and stator winding inter-turn faults in WRIM using simulated MEC model and experimental results," Electric Power Systems Research, vol. 119, pp. 418-424, 2015.

[9] Y.-G. Li, H.-M. Li, H. Zhao, and S.-T. Wan, "Fault identification method of rotor inter turn short-circuit using stator winding detection," Proceedings of the Chinese Society for Electrical Engineering, vol. 2, no. 2, pp. 856-860, 2004.

[10] S.-T. Wan, H.-M. Li, and Z.-F. Xu, "Analysis of generator vibration characteristic on stator winding inter-turn short circuit fault," Proceedings of the Chinese Society for Electrical Engineering, vol. 4, no. 24, pp. 57-161, 2004.

[11] C. T. Kowalski and T. Orlowska-Kowalska, "Neural networks application for induction motor faults diagnosis," Mathematics and Computers in Simulation, vol. 63, no. 3-5, pp. 435-448, 2003.
[12] J.-W. Zhang, Q. Yao, N.-H. Zhu, L. Yang, and Q. Lu, "Method for diagnosing the stator winding faults in squirrel cage induction motor," High Voltage Engineering, vol. 6, no. 33, pp. 114-117, 2007.

[13] X.-G. Hou, Z.-G. Wu, L. Xia, and L.-P. Bu, "Application of instantaneous power decomposition technique in induction motors stator fault diagnosis," in Proceedings of the Chinese Society for Electrical Engineering, vol. 25, pp. 110-115, 2005.

[14] M. R. Mehrjou, N. Mariun, M. Hamiruce Marhaban, and N. Misron, "Rotor fault condition monitoring techniques for squirrel-cage induction machine-a review," Mechanical Systems and Signal Processing, vol. 25, no. 8, pp. 2827-2848, 2011.

[15] G. G. Acosta, C. J. Verucchi, and E. R. Gelso, "A current monitoring system for diagnosing electrical failures in induction motors," Mechanical Systems and Signal Processing, vol. 20, no. 4, pp. 953-965, 2006.

[16] K. N. Gyftakis, A. J. M. Cardoso, and J. A. Antonino-Daviu, "Introducing the filtered park's and filtered extended park's vector approach to detect broken rotor bars in induction motors independently from the rotor slots number," Mechanical Systems and Signal Processing, vol. 93, no. 1, pp. 30-50, 2017.

[17] I. Aydin, M. Karakose, and E. Akin, "A new method for early fault detection and diagnosis of broken rotor bars," Energy Conversion and Management, vol. 52, no. 4, pp. 1790-1799, 2011.

[18] M. Abd-el-Malek, A. K. Abdelsalam, and O. E. Hassan, "Induction motor broken rotor bar fault location detection through envelope analysis of start-up current using hilbert transform," Mechanical Systems and Signal Processing, vol. 93, no. 1, pp. 332350, 2017.

[19] Y. Shao, "Feature extracting method of stator and rotor faults of induction motor by Park vector rotating filter," Electric Machines and Control, vol. 14, no. 143, pp. 57-61, 2010.

[20] T. Lobos, Z. Leonowicz, J. Szymanda, and P. Ruczewski, "Application of higher-order spectra for signal processing in electrical power engineering," COMPEL-The International Journal for Computation and Mathematics in Electrical and Electronic Engineering, vol. 17, no. 5, pp. 602-611, 1998.

[21] Y. Liu, L. Guo, Q. Wang, G. An, M. Guo, and H. Lian, "Application to induction motor faults diagnosis of the amplitude recovery method combined with FFT,' Mechanical Systems and Signal Processing, vol. 24, no. 8, pp. 2961-2971, 2010.

[22] X.-F. Liu, S.-J. Cheng, and J.-Y. Wen, "An improved method of instantaneous symmetrical compnents and its detection for positive and negative sequence current," Proceedings of the Chinese Society for Electrical Engineering, vol. 28, no. 1, pp. 52$58,2008$.

[23] F. Gu, T. Wang, A. Alwodai, X. Tian, Y. Shao, and A. D. Ball, "A new method of accurate broken rotor bar diagnosis based on modulation signal bispectrum analysis of motor current signals," Mechanical Systems and Signal Processing, vol. 50-51, no. 1, pp. 400-413, 2015.

[24] M. O. Mustafa, G. Nikolakopoulos, T. Gustafsson, and D. Kominiak, "A fault detection scheme based on minimum identified uncertainty bounds violation for broken rotor bars in induction motors," Control Engineering Practice, vol. 48, pp. 63-77, 2016. 


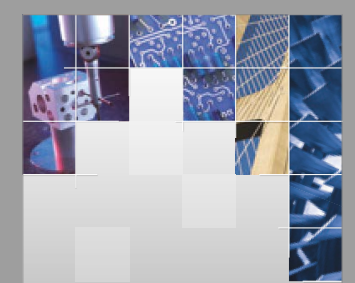

\section{Enfincering}
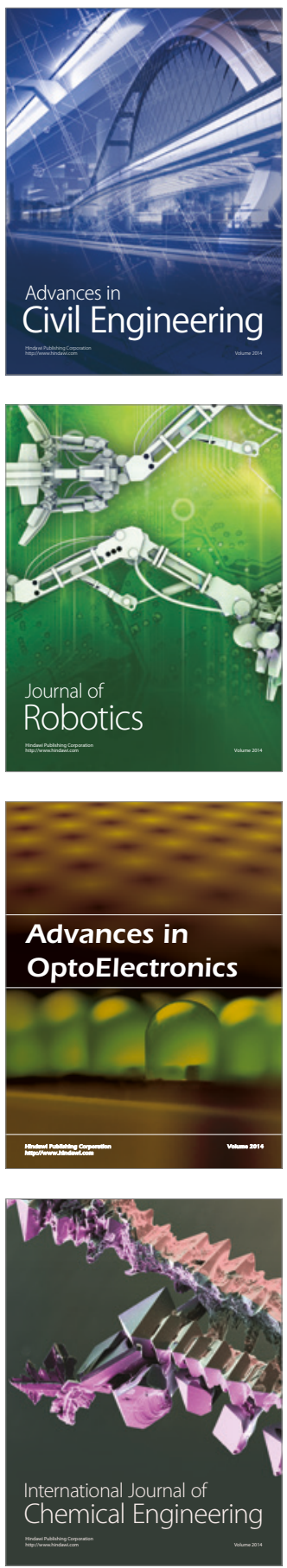

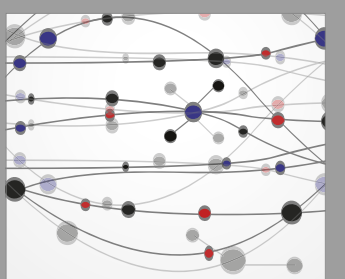

The Scientific World Journal

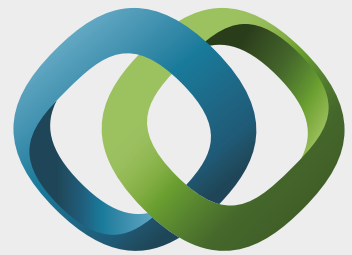

\section{Hindawi}

Submit your manuscripts at

https://www.hindawi.com
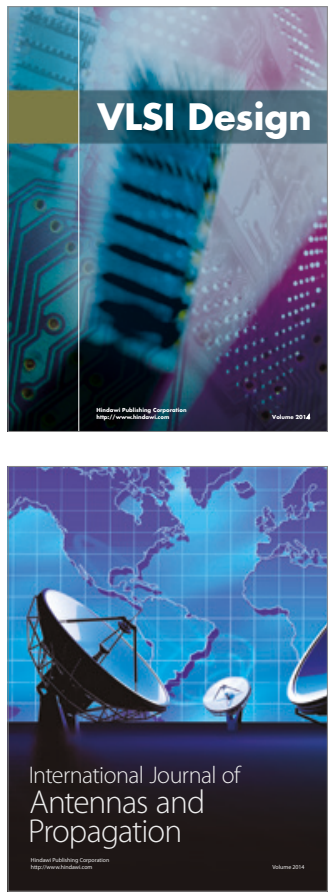

\section{Rotating}

Machinery
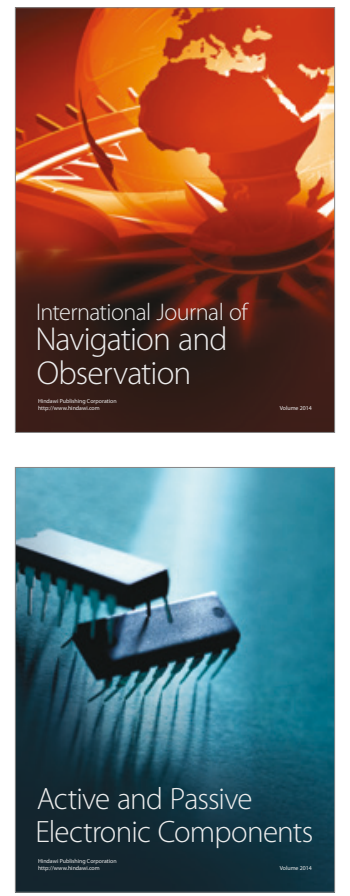
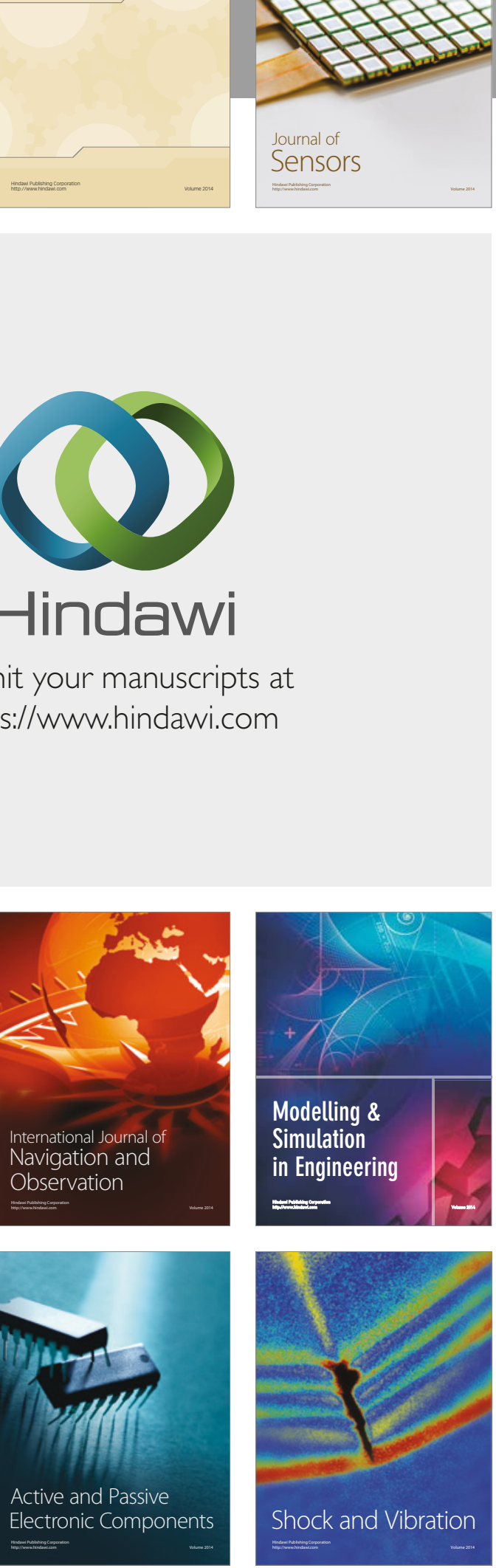
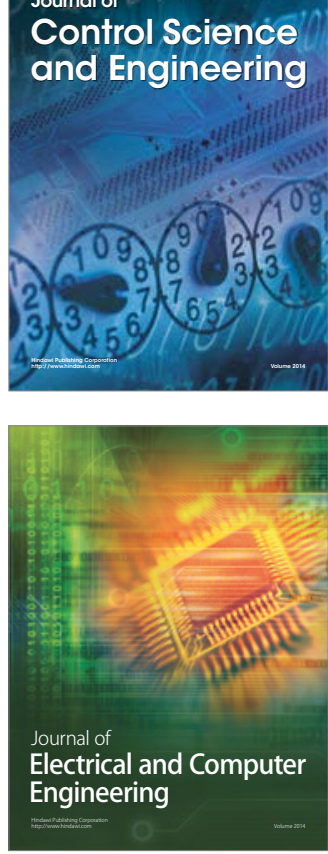

Distributed

Journal of

Control Science

and Engineering
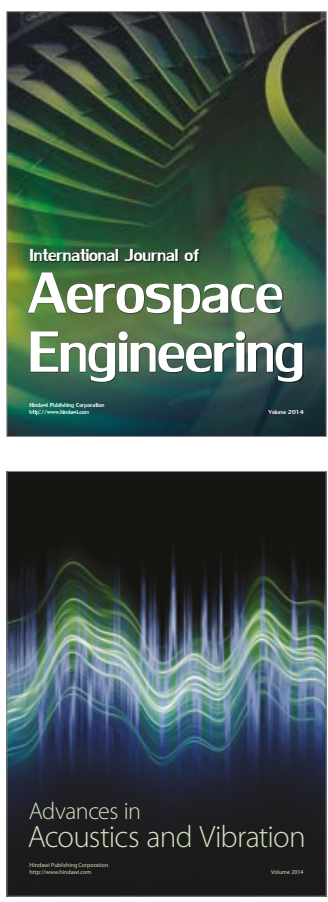

Sensor Networks 